\title{
Prevalence and non-invasive predictors of left main or three-vessel coronary disease: evidence from a collaborative international meta-analysis including 22740 patients
}

\author{
Fabrizio D'Ascenzo, ${ }^{1,11}$ Davide Giacomo Presutti, ${ }^{1}$ Elisa Picardi, ${ }^{1}$ Claudio Moretti, ${ }^{1,11}$ \\ Pierluigi Omedè, ${ }^{1}$ Filippo Sciuto, ${ }^{1}$ Marco Novara, ${ }^{1}$ Andrew T Yan, ${ }^{2}$ \\ Shaun Goodman, ${ }^{2}$ Nitin Mahajan, ${ }^{3}$ Masami Kosuge, ${ }^{4}$ Alberto Palazzuoli, ${ }^{5}$ \\ Gwo-Ping Jong, ${ }^{6}$ Hussain Isma'eel, ${ }^{7}$ Matthew J Budoff, ${ }^{7}$ Ronen Rubinshtein, ${ }^{8}$ \\ Henry Gewirtz, ${ }^{9}$ Matthew J Reed, ${ }^{10}$ Pierre Theroux, ${ }^{11}$ Giuseppe Biondi-Zoccai, ${ }^{10,11}$ \\ Maria Grazia Modena, ${ }^{10}$ Imad Sheiban, ${ }^{1}$ Fiorenzo Gaita ${ }^{1}$
}

\begin{abstract}
- An appendix is published online only. To view this file please visit the journal online (http://heart.bmj.com/content/ 98/12.toc).

For numbered affiliations see end of article.
\end{abstract}

\section{Correspondence to} Dr Fabrizio D’Ascenzo, Division of Cardiology, University of Turin, S Giovanni Battista 'Molinette' Hospital, Corso Bramante 88-90, Turin 10126, Italy:

fabrizio.dascenzo@gmail.com

Accepted 17 April 2012

\section{ABSTRACT}

Background Left main disease (LMD) and three-vessel disease (3VD) have important prognostic value in patients with coronary artery disease. However, uncertainties still exist about their prevalence and predictors in patients with acute coronary syndrome (ACS) and also in patients with stable coronary disease. Thus the aim of this study was to perform an international collaborative systematic review and metaanalysis to appraise the prevalence and predictors of LMD and 3VD.

Methods Medline/PubMed were systematically searched for eligible studies published up to 2010, reporting multivariate predictors of LMD or 3VD. Study features, patient characteristics, and prevalence and predictors of LMD and 3VD were abstracted and pooled with random-effect methods (95\% Cls).

Results 17 studies (22 740 patients) were included, 11 focusing on ACS (17896 patients) and six on stable coronary disease (4844 patients). In the ACS subgroup, LMD or 3 VD occurred in $20 \%(95 \% \mathrm{Cl} 7.2 \%$ to $33.4 \%)$, LMD in $12 \%$ (95\% Cl $10.5 \%$ to $13.5 \%)$, and $3 \mathrm{VD}$ in $25 \%$ (95\% Cl $23.1 \%$ to $27.0 \%)$. Heart failure at admission and extent of ST-segment elevation in lead aVR on 12-lead ECG were the most powerful predictors of LMD or 3VD. In the stable disease subgroup, LMD or 3VD was found in $36 \%(95 \% \mathrm{Cl} 18.5 \%$ to $48.8 \%)$, with the most powerful predictors being transient ischaemic dilation during the imaging stress test, extent of ST-segment elevation in aVR and V1 during the stress test, and hyperlipidaemia.

Conclusions This meta-analysis demonstrated that severe coronary disease - that is, LMD or 3VD-is more common in patients with ACS or stable coronary disease than generally perceived, and that simple and low-cost tools may help in the selection of the most appropriate therapeutic approach.

\section{INTRODUCTION}

Left main coronary disease (LMD) and three-vessel coronary disease (3VD) carry a high risk of death and adverse events in both stable and unstable clinical settings. ${ }^{1} 2$ This poor prognosis may be improved in selected patients by percutaneous or surgical revascularisation, ${ }^{1-3}$ but invasive interventions are often not carried out because of underestimation and poor definition of patient risk. For example, in a large contemporary registry, percutaneous coronary intervention was performed in only $70 \%$ of patients with acute myocardial infarction and $35 \%$ of patients with unstable angina. $^{4}$

Clearly, reliable and independent predictors of LMD and/or 3VD could be helpful in order to focus resources and aggressive therapies to this high-risk subset of patients.

A few studies have addressed these issues in various populations, ${ }^{5}{ }^{6}$ but, to our knowledge, no meta-analyses have been performed to globally assess them. We therefore performed a systematic review focusing on (1) the incidence of $\mathrm{LMD}$ or $3 \mathrm{VD}$, and (2) their non-invasive predictors.

\section{METHODS}

The main objective of this study was to identify multivariate predictors of $\mathrm{LMD}$ or $3 \mathrm{VD}$ using a meta-analytical approach. Current guidelines were followed during the course of the present research, in particular the recent Preferred Reporting Items for Systematic reviews and MetaAnalyses (PRISMA) amendment to the Quality of Reporting of Meta-analyses (QUOROM) statement, and recommendations from The Cochrane Collaboration and Meta-analysis Of Observational Studies in Epidemiology (MOOSE). ${ }^{7-11} 14$

\section{Search strategy and study selection}

Medline, Cochrane Library and Biomed Central were systematically appraised in keeping with established methods ${ }^{12}$ with highly specific terms 'left main* OR multivessel disease* and predictor (NOT (review(pt) OR editorial(pt) OR letter(pt))'.

Two independent reviewers (GB-Z, FDA) first analysed selected citations at the title and/or abstract level, with disagreements resolved after 
consensus. If potentially pertinent, studies were then appraised as complete reports according to the following explicit selection criteria. Inclusion criteria were (all had to be met for inclusion) studies that (1) investigated patients presenting with acute coronary syndrome (ACS) or patients with stable angina or instrumental ischaemia, (2) reported predictors of LMD or 3VD identified through multivariate analysis, and (3) defined 3VD as a significant stenosis in all three main epicardial coronary arteries. Exclusion criteria were non-human studies and duplicate reporting (in which case the article reporting on the largest sample was retained).

\section{Data extraction}

The same two investigators independently and in a blinded fashion tabulated the data of all studies qualifying for the metaanalysis and also contacted the corresponding authors for additional information. ${ }^{13}$ Data collected included authorship, journal and year of publication, country of origin, baseline demographic and clinical features (eg, risk factors, previous percutaneous or surgical revascularisation, indication for angiography), and independent predictors of LMD or 3VD. They were reported both as frequencies in different studies and with their power of prediction, evaluated as $\mathrm{OR}$.

\section{Internal validity and quality appraisal}

The quality of each manuscript was graded using a modified MOOSE code taking into account the specific features of each study, ${ }^{9}$ with regard to design, setting, data source, statistical approach to multivariate analysis. A score of zero was assigned to retrospective and single-centre studies, and a score of one to prospective and multicentre studies. Studies with potential study bias in selection, adjudication, detection and attrition were ascertained as low with no bias identified, moderate with one identified, and high with two identified or when bias could not be assessed. An overall credibility index was built on all these parameters, with a score of 10 implying a very high credibility index, and 7-9, 4-6, 1-3 and 0 indicating high, moderate, low and very low indices, respectively.

\section{Data analysis and synthesis}

Continuous variables are reported as mean (SD) or median (range). Categorical variables are expressed as $\mathrm{n} / \mathrm{N}$ (\%). Statistical pooling was performed according to a random-effects model with generic inverse-variance weighting, computing risk estimates with 95\% CIs, using RevMan 5 (The Cochrane Collaboration, The Nordic Cochrane Centre, and Copenhagen, Denmark). Fixed effect was also appraised, and reported only if different results from random were found. Independent predictors were reported according to the number of studies in which they were evaluated and weighted according to their OR. Smallstudy bias was appraised by graphical inspection of funnel plots. Standard hypothesis testing was set at the two-tailed 0.05 level.

\begin{tabular}{|c|c|c|}
\hline $\begin{array}{c}260 \text { citations identified from } \\
\text { database search }\end{array}$ & $\begin{array}{c}2 \text { additional citations } \\
\text { obtained from other sources }\end{array}$ \\
$\qquad$\begin{tabular}{|c|c|c|}
23 full text articles appraised \\
according to selection criteria
\end{tabular} & $\begin{array}{c}\text { 3 excluded because not } \\
\text { reporting independent } \\
\text { predictors of vessels disease; } \\
2 \text { because of overlapping } \\
\text { data; } \\
\text { the systematic review }\end{array}$ \\
1 because appraising only end \\
stage kidney disease;
\end{tabular} \mid

Figure 1 Review profile.
Table 1 Key patient characteristics

\begin{tabular}{|c|c|c|}
\hline Characteristic & $\begin{array}{l}\text { ACS studies } \\
(n=17896)\end{array}$ & $\begin{array}{l}\text { Stable patients } \\
(\mathrm{n}=4844)\end{array}$ \\
\hline Age (years) & $65(60-66)$ & $62(60-65)$ \\
\hline Male gender & $64 \%(60-71)$ & $70 \%(65-73)$ \\
\hline Diabetes & $34 \%(27-36)$ & $35 \%(20-39)$ \\
\hline Hypertension & $66 \%(57-76)$ & $62 \%(60-70)$ \\
\hline Dyslipidaemia & $49 \%(46-57)$ & $52 \%(40-64)$ \\
\hline $\begin{array}{l}\text { Prior cardiac events (both myocardial } \\
\text { ischaemia and revascularisation*) }\end{array}$ & $47.5 \%(40-58)$ & $20 \%(18-26)$ \\
\hline Admitted with unstable angina & $58 \%(40-309)$ & - \\
\hline Admitted with acute myocardial infarction & $80 \%(54-150)$ & - \\
\hline $\begin{array}{l}\text { Admitted with non-ST segment elevation } \\
\text { myocardial infarction }\end{array}$ & $65 \%(30-250)$ & - \\
\hline $\begin{array}{l}\text { Admitted with ST segment elevation } \\
\text { myocardial infarction }\end{array}$ & $71 \%(61-87)$ & - \\
\hline $\begin{array}{l}\text { Admitted with chest pain with positive } \\
\text { stress test }\end{array}$ & - & $10 \%(9-12)$ \\
\hline $\begin{array}{l}\text { Consecutive patients undergoing percutaneous } \\
\text { coronary revascularisation, with documented } \\
\text { angina or positive ischaemia test }\end{array}$ & & $80 \%(70-87)$ \\
\hline $\begin{array}{l}\text { Asymptomatic diabetic patients (a research } \\
\text { protocol) }\end{array}$ & & $10 \%$ \\
\hline
\end{tabular}

Values are \% or median (1st-3rd quartile).

*Including previous acute myocardial infarction, surgical and percutaneous revascularisation.

ACS, acute coronary syndrome.

\section{RESULTS}

Figure 1 summarises the 17 studies that were found by the search and retained for analysis with a total of 22740 patients $^{15-31}$; 11 focused on ACS $(n=17896)^{15-25}$ and six on stable coronary disease $(n=4844) .{ }^{26-31}$

Baseline features of patients with ACS and stable coronary disease are reported in table 1 . Most of the patients were older than 60 years, and were male in almost two-thirds of the cases. Rates of cardiovascular risk factors were similar for patients with stable and unstable coronary disease, while previous cardiovascular events were more commonly reported in patients with ACS (48\% vs 20\%). The latter were more often admitted for acute myocardial infarction, especially ST elevation myocardial infarction (up to $70 \%$ ), while patients with stable disease most often underwent coronary angiography because of symptoms (80\%) or laboratory evidence of ischaemia (10\%).

In $68 \%$ of the studies, physicians appraising the ECG were blinded to the angiography results. The definition of coronary vessel stenosis, other than $\mathrm{LMD}$ stenosis, was more than $75 \%$ in $57 \%$ of the studies.

Among patients with ACS, the prevalence of LM or 3V disease was $20 \%$ (95\% CI $7.2 \%$ to $33.4 \%$ ), the prevalence of LM disease alone was $12 \%$ (95\% CI $10.45 \%$ to $13.5 \%$ ), and the prevalence of

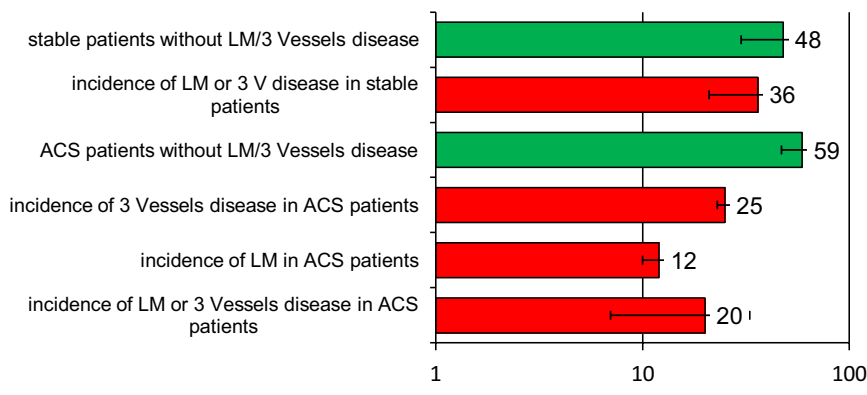

Figure 2 Prevalence of left main (LM) and three-vessel disease (reported as percentages) in stable patients and patients with acute coronary syndrome. 
Table 2 Most common non-invasive predictors of left main and three-vessel disease in patients presenting with acute coronary syndrome

\begin{tabular}{|c|c|c|c|c|}
\hline Predictor & $\begin{array}{l}\text { No of overall } \\
\text { studies }(N=11)(\%)\end{array}$ & $\begin{array}{l}\text { No of studies reporting } \\
\text { both LMD and 3VD } \\
\text { predictors }(\mathrm{N}=3)(\%)\end{array}$ & $\begin{array}{l}\text { No of studies reporting } \\
\text { only multivessel } \\
\text { predictors }(N=6)(\%)\end{array}$ & $\begin{array}{l}\text { No of studies reporting } \\
\text { only LMD predictors } \\
(\mathrm{N}=2)(\%)\end{array}$ \\
\hline Age (per decade increase) & $3(27)$ & $1(33)$ & $2(33)$ & - \\
\hline Male gender & $3(27)$ & $1(33)$ & $1(17)$ & $1(50)$ \\
\hline Positive biomarkers (troponins) & $1(20)$ & - & - & $1(50)$ \\
\hline History of coronary artery disease & $3(27)$ & $1(33)$ & $1(17)$ & $1(50)$ \\
\hline Peripheral artery disease & $2(18)$ & $1(33)$ & $1(17)$ & - \\
\hline Diabetes mellitus & $2(18)$ & $1(33)$ & $1(17)$ & - \\
\hline Heart rate (per 10 beats/min increase) & $2(18)$ & $1(33)$ & $1(17)$ & - \\
\hline TIMI risk score (for points increase) & $1(9)$ & $1(33)$ & - & - \\
\hline Pro-BNP & 1 (9) & - & $1(17)$ & - \\
\hline Previous use of aspirin & $1(9)$ & 1 (9) & - & $1(50)$ \\
\hline
\end{tabular}

3VD, three-vessel disease; BNP, B-type natriuretic peptide; LMD, left main disease; TIMI, Thrombolysis In Myocardial Infarction risk score.

3V disease alone was $25 \%$ (95\% CI $23.1 \%$ to $27.0 \%$ ) (figure 2 ). The most common predictors are reported in table 2 Heart failure at clinical presentation (reported in $18 \%$ of studies) and degree of ST elevation in lead aVR (reported in $27 \%$ of cases) were the most powerful predictors (figure 3).

In stable patients, as reported in figure 2 , the overall incidence of $\mathrm{LMD}$ or $3 \mathrm{VD}$ was $36 \%$ (95\% CI $18.5 \%$ to $48.8 \%$ ), with the most powerful predictors being transient ischaemic dilation (TID) during myocardial perfusion imaging, lead aVR and V1 elevation during the stress test, and hyperlipidaemia (all reported in $9 \%$ of studies: table 3 , figure 4 ).

The most important methodological features of these studies, and their internal validity, are reported in tables A and B (online appendix). Briefly, most were single-centre studies performed more commonly in North America and Asia, used a logistic regression model, and were assessed as having moderate overall credibility by our criteria.

\section{DISCUSSION}

The key findings of our study are: (a) LMD and 3VD are common clinical conditions, more common than generally expected, in both stable and unstable coronary disease; (b) simple, inexpensive and readily available clinical and laboratory tests may be helpful for screening patients with these high-risk conditions to enable them to receive optimal treatment.
Patients with 3VD and LMD have been the subject of several investigations to assess the best revascularisation procedure ${ }^{32}$ For this reason, it is useful to know of tools that could quickly identify this condition or raise a strong clinical suspicion.

Our meta-analysis provides interesting information from an epidemiological point of view, revealing the most powerful predictors of LMD and $3 \mathrm{VD}$ in patients with ACS and stable angina. In ACS, the prevalence of LMD and 3VD was $20.13 \%$, the prevalence of $\mathrm{LMD}$ alone was $12 \%$, and the prevalence of 3VD alone was $25.7 \%$ among patients who underwent coronary angiography. In this group, the most powerful predictors of LMD or $3 \mathrm{VD}$ were degree of ST elevation in lead aVR and heart failure. In patients with stable coronary disease, the prevalence of $\mathrm{LMD}$ and $3 \mathrm{VD}$ was $33.5 \%$, and the most powerful predictor of these conditions was TID during myocardial perfusion imaging. Our percentage of LMD is slightly higher than literature data. In fact, although there are no specific studies on incidence and prevalence of LMD and ACS, in retrospective analysis including all subjects who underwent angiography for suspected coronary artery disease, this condition was found in $4.7-9 \% .^{36-38}$ In our meta-analysis, one in four patients with ACS was affected by $3 \mathrm{VD}$; this rate is higher than reported in data extrapolated from CADILLAC (15.6\%) and Stent-PAMI 1 (13.18\%) (two studies on primary percutaneous coronary intervention), but similar to other trials. ${ }^{39} 40$ These differences may
Figure 3 Most powerful predictors of left main disease/three-vessel disease in patients with acute coronary syndrome (reported as OR). * Obtained in study reporting only left main disease predictors. ${ }^{* *}$ Obtained in study reporting left main and three-vessel disease predictors. Thrombolysis In Myocardial Infarction risk score (TIMI).

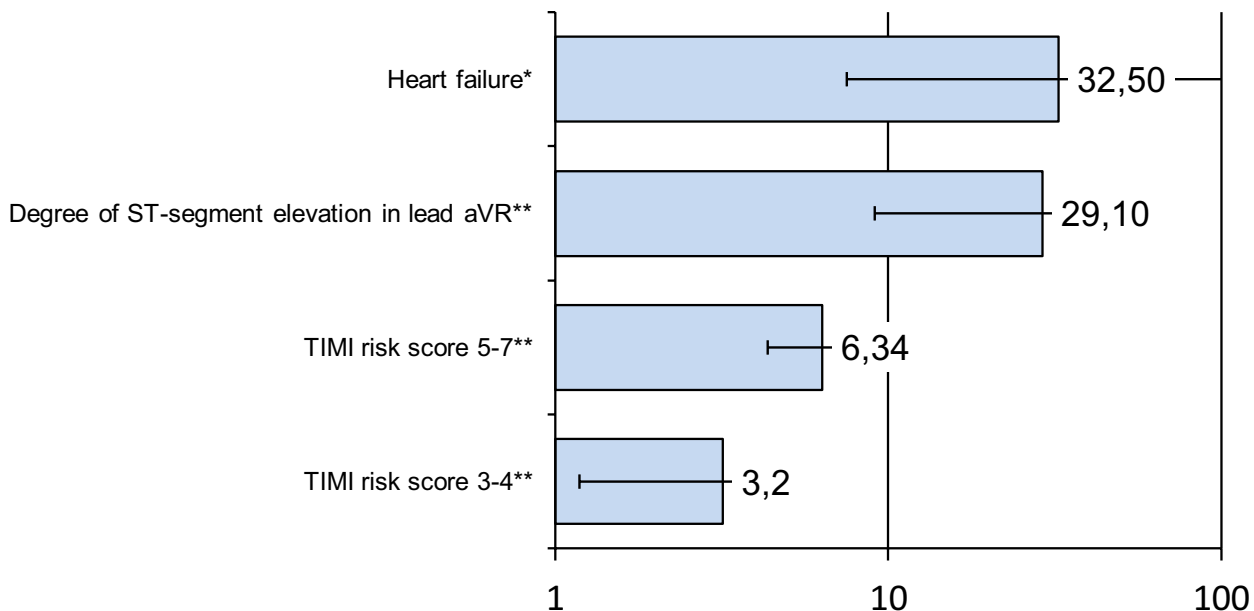


Table 3 Most common non-invasive predictors of left main and threevessel disease in stable patients (reported as percentages and absolute values)

\begin{tabular}{ll}
\hline Predictor & No (\%) (N=6) \\
\hline Age (per decade) & $2(18)$ \\
Lead aVR ST elevation during stress test & $1(9)$ \\
Lead V1 ST elevation during stress test & $1(9)$ \\
Leads V4, V5, V6, II, III, aVF depression during stress test & $1(9)$ \\
Transient ischaemic dilation during myocardial perfusion imaging & $1(9)$ \\
Pregnancy-associated plasma protein-A levels & $1(9)$ \\
Coronary artery calcification score & $1(9)$ \\
Male gender & $1(9)$ \\
\hline
\end{tabular}

be related to the absence of a uniform definition of 3VD which would allow a precise comparison between different studies. In the stable patients, one in three had either LMD or 3VD. Baseline characteristics of patients in the COURAGE study show a slightly lower percentage (25\%) with $3 \mathrm{VD}$. However, it should be remembered that, in this trial, patients with unprotected LMD were excluded. ${ }^{39}$ A more accurate comparison can be performed with the analysis of the subgroup of patients with high-risk coronary disease in the CASS registry, which reported that $8 \%$ of women and $27 \%$ of men with stable chest pain and no history of myocardial infarction had LMD or 3VD..$^{40}$

Another important aspect to consider is that we found the most powerful predictors of $3 \mathrm{VD}$ and LMD to be ST elevation in lead aVR and a clinical finding of heart failure. It is important to emphasise this finding because it means that clinical examination and the 'plain old 12-lead ECG' are still among the top predictors in the evaluation of ACS, even though new technologies are assuming an increasing role. ${ }^{41-44}$ Moreover, this could be very useful in the clinical evaluation of unstable disease: if $\mathrm{LMD}$ is suspected, ergometric tests should be avoided because of potential risk, and an invasive diagnostic study should be performed.

Several editorials have suggested that lead aVR was of little help in ECG analysis, as it provides only reciprocal information from the left lateral side, whereas its original purpose was to explore the outflow tract of the right ventricle and the basal part of the septum located in the upper right side of the heart. ${ }^{45} 46$ In contrast, several clinical studies have shown that ST elevation in lead aVR was not only helpful in identifying severe coronary artery disease, but could also be a predictor of adverse outcome in ACS ${ }^{4-48}$ Assessment of baseline ECG and an eventual stress test can provide useful prognostic information. ${ }^{49}$ For this reason, they are both taken into account in current clinical practice, ${ }^{50} 51$ despite their unclear predictive value, which goes beyond the aim of the present study.

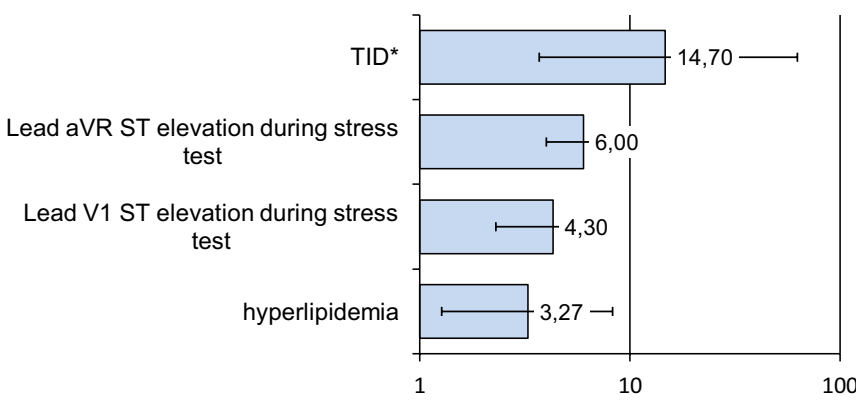

Figure 4 Most powerful predictors of left main disease/three-vessel disease in stable patients (reported as OR). ${ }^{*}$ Transient ischaemic dilation during myocardial perfusion imaging.
Similar considerations can be made about heart failure and ACS. In fact, the GRACE study group has amply shown that Killip class is a powerful predictor of in-hospital and 6-month mortality in ACS $^{52}$ In 2005, the CADILLAC group documented that heart failure was a predictor of 1-year mortality among patients with ST elevation myocardial infarction; this study also showed that the presence of $3 \mathrm{VD}$ was also a powerful prognostic factor. ${ }^{39} \mathrm{~A}$ correlation between extent of coronary artery disease and heart failure was underlined by Haim et $a l^{42}$ in a large European survey of outcome of 2529 patients with ACS complicated by symptomatic heart failure. In fact, prevalence of $3 \mathrm{VD}$ and $\mathrm{LMD}$ in these subjects was significantly higher than in other patients.

Finally, with regard to stable patients, we found that the most powerful predictor of LMD or 3VD was TID during myocardial perfusion imaging. Our result confirms medical literature data that consider TID to be an important marker of both 3VD and $\mathrm{LMD}^{52}$ and it is interesting that similar observations were obtained in patients undergoing stress echocardiography. ${ }^{53}$ However, Valdiviezo et al reported that TID does not increase the likelihood or severity of coronary artery disease in patients with otherwise normal SPECT (Single-photon emission computed tomography) radionuclide myocardial perfusion images. ${ }^{54-56}$

Our work has several limitations. First, the prevalence data were limited to a small subset of patients, because of our strategy to include studies that used multivariate analyses to define predictors. Second, no pooling was made of predictors, and, as the most common predictors are not necessarily the most powerful ones, a bias was created in selecting the ones that were most often reported. ${ }^{57-59}$ Prospective studies would give a different perspective, as they would use predefined parameters; however, the present approach gives a wider perspective across the existing literature. Another important limitation is that we could not obtain discrete data on the relative incidence of LMD versus $3 \mathrm{VD}$ in patients with stable angina, and therefore could not distinguish between predictors of LMD and BVD. However, the data remain clinically useful, as these two groups of patients can generally benefit from angiography with a view towards interventional therapy. Finally, the epidemiological data were obtained from analysis of cohorts of prospective and retrospective studies, which may be influenced by recruitment bias. This may lead to some differences compared with the 'real world'. The funnel plot (figure 5) is skewed in showing only the more precise larger studies. A final limitation was that patient-level data were not used.

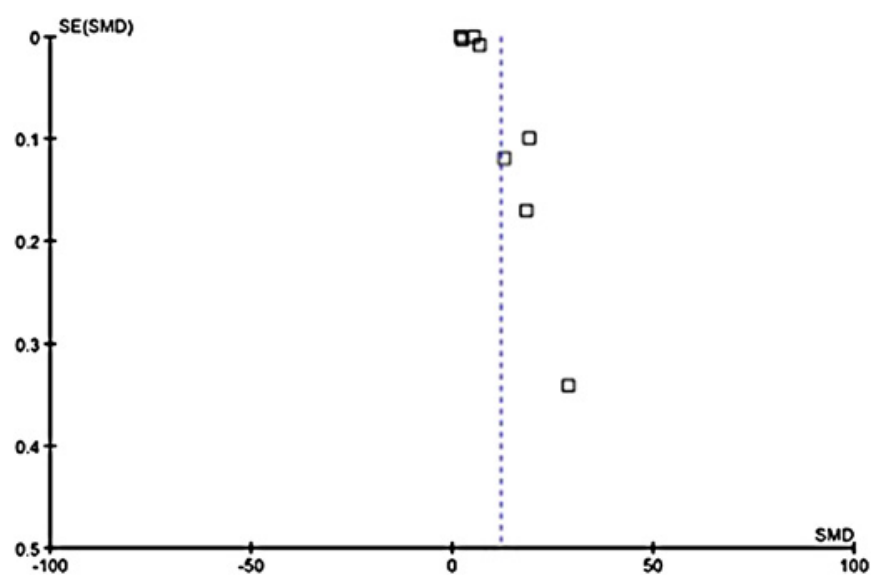

Figure 5 Funnel plot. 


\section{Author affiliations}

${ }^{1}$ Division of Cardiology, University of Turin, Turin, Italy

${ }^{2}$ Department of Medicine, Maimonides Medical Center, Brooklyn, New York, USA

${ }^{3}$ Division of Cardiology, Yokohama City University Medical Center, Yokohama, Japan

${ }^{4}$ Department of Internal Medicine and Metabolic Diseases, Section of Cardiology,

University of Siena, Siena, Italy

${ }^{5}$ Community Medical Research Center, Institute of Public Health, National Yang-Ming University, Yang-Ming, China

${ }^{6}$ American University of Beirut Medical Center, Beirut, Lebanon

${ }^{7}$ The Department of Cardiovascular Medicine, Lady Davis Carmel Medical Center and the Ruth and Bruce Rappaport School of Medicine, Technion-IIT, Haifa, Israel ${ }^{8}$ Department of Medicine, Cardiology Division, Massachusetts General Hospital, Harvard Medical School, Boston, Massachusetts, USA

${ }^{9}$ St Michael's Hospital, University of Toronto and Canadian Heart Research Centre, Toronto, Canada

${ }^{10}$ Division of Cardiology, University of Modena and Reggio Emilia, Modena, Italy

${ }^{11}$ Meta-analysis and Evidence based medicine Training in Cardiology (METCARDIO), Ospedaletti, Italy

Acknowledgements This work was inspired by an 81-year-old male patient, who, after recently being discharged from another institution for an NSTEMI with ST elevation in aVR without invasive assessment, was successfully revascularised with a drug-eluting stent implanted in the left main coronary artery at our institution because of ongoing cardiogenic shock. A telephone follow-up revealed that he is in good clinical condition (CCS, Canadian Class Society, I).

Contributors FDA conceived and designed the study and wrote the paper. GBZ and IS supervised the conduct of the trial and data collection. GBZ, IS and FDA provided statistical advice on study design and analysed the data; all authors contributed substantially to its revision. FDA takes responsibility for the paper as a whole. FDA, GBZ and IS had full access to all of the data in the study and take responsibility for the integrity of the data and the accuracy of the data analysis. All the authors were involved in the writing and approved the manuscript.

Competing interests None.

Patient consent Obtained.

Ethics approval Division of Cardiology, University of Turin.

Provenance and peer review Not commissioned; internally peer reviewed.

\section{REFERENCES}

1. Boudriot E, Thiele $\mathrm{H}$, Walther $\mathrm{T}$, et al. Randomized comparison of percutaneous coronary intervention with sirolimus-eluting stents versus coronary artery bypass grafting in unprotected left main stem stenosis. J Am Coll Cardiol 2011; 57:538-45.

2. Levine GN, Bates ER, Blankenship JC, et al. ACCF/AHA/SCAl guideline for percutaneous coronary intervention: executive summary: a report of the American College of Cardiology Foundation/American heart Association Task Force on practice guidelines and the Society for cardiovascular angiography and interventions. Catheter Cardiovasc Interv 2012;79:453-95.

3. Lee MS, Sillano D, Latib A, et al. Multicenter international registry of unprotected left main coronary artery percutaneous coronary intervention with drug-eluting stents in patients with myocardial infarction. Catheter Cardiovasc Interv 2009; 73:15-21.

4. Fox KA, Carruthers KF, Dunbar DR, et al. Underestimated and under-recognized: the late consequences of acute coronary syndrome (GRACE UK-Belgian Study). Eur Heart J 2010:31:2755-64.

5. Engelen DJ, Gorgels AP, Cheriex EC, et al. Value of the electrocardiogram in localizing the occlusion site in the left anterior descending coronary artery in acute anterior myocardial infarction. J Am Coll Cardiol 1999;34:389-95.

6. Gorgels AP, Vos MA, Mulleneers R, et al. Value of the electrocardiogram in diagnosing the number of severely narrowed coronary arteries in rest angina pectoris. Am J Cardiol 1993;72:999-1003.

7. Moher D, Liberati A, Tetzlaff J, et al; PRISMA Group. Preferred reporting items for systematic reviews and meta-analyses: the PRISMA statement. BMJ 2009;339: b2535.

8. Moher D, Cook DJ, Eastwood S, et al. Improving the quality of reports of metaanalyses of randomised controlled trials: the QUOROM statement. Quality of reporting of meta-analyses. Lancet 1999;354:1896-900.

9. Stroup DF, Berlin JA, Morton SC, et al. Meta-analysis of observational studies in epidemiology: a proposal for reporting. Meta-analysis of observational studies in epidemiology (MOOSE) group. JAMA 2000;283:2008-12.

10. Higgins JPT, Green S, eds. Cochrane Handbook for Systematic Reviews of Interventions Version 5.0.2. The Cochrane Collaboration, 2009. http://www.cochranehandbook.org

11. Biondi-Zoccai GG, Lotrionte M, Abbate A, et al. Compliance with OUOROM and quality of reporting of overlapping meta-analyses on the role of acetylcysteine in the prevention of contrast associated nephropathy: case study. BMJ 2006;332:202-9.
12. Wilczynski NL, Haynes RB; for the Hedges Team. Developing optimal search strategies for detecting clinically sound prognostic studies in MEDLINE: an analytic survey. BMC Med 2004;2:23.

13. McManus RJ, Wilson S, Delaney BC, et al. Review of the usefulness of contacting other experts when conducting a literature search for systematic reviews. BMJ 1998:317:1562-3.

14. Higgins JPT, Thompson SG, Deeks JJ, et al. Measuring inconsistency in metaanalyses. BMJ 2003;327:557-60.

15. Badran HM, Elnoamany MF, Khalil TS, et al. Age-related alteration of risk profile, inflammatory response, and angiographic findings in patients with acute coronary syndrome. Clin Med Cardiol 2009;3:15-28.

16. Claver E, Curós A, López-Ayerbe J, et al. Clinical predictors of left main coronary artery disease in high-risk patients with a first episode of non-ST-segment elevation acute coronary syndrome. Rev Esp Cardiol 2007;59:794-800.

17. Garcia S, Canoniero M, Peter A, et al. Correlation of TIMl risk score with angiographic severity and extent of coronary artery disease in patients with non-ST elevation acute coronary syndromes. Am J Cardiol 2004:93:813-16.

18. Jong GP, Ma T, Chou P, et al. Reciprocal changes in 12-lead electrocardiography can predict left main coronary artery lesion in patients with acute myocardial infarction. Int Heart J 2006:47:13-20.

19. Kini AS, Lee PC, Mitre CA, et al. Prediction of outcome after percutaneous coronary intervention for the acute coronary syndrome. Am J Med 2003;115:708-14.

20. Kosuge M, Ebina T, Hibi K, et al. An early and simple predictor of severe left main and/or three-vessel disease in patients with non-ST-segment elevation acute coronary syndrome. Am J Cardiol 2011;107:495-500.

21. Mahajan N, Hollander G, Thekkoott D, et al. Prediction of left main coronary artery obstruction by 12-lead electrocardiography: ST segment deviation in lead V6 greate than or equal to ST segment deviation in lead V1. Ann Noninvasive Electrocardiol 2006;11:102-12

22. Mega JL, Morrow DA, Sabatine MS, et al. Correlation between the TIMI risk score and high-risk angiographic findings in non-ST-elevation acute coronary syndromes: observations from the platelet receptor inhibition in ischemic syndrome management in patients limited by unstable signs and symptoms (PRISM-PLUS) trial. Am Heart $J$ 2005:149:846-50.

23. Yamaji H, Iwasaki K, Kusachi S, et al. Prediction of acute left main coronary artery obstruction by 12-lead electrocardiography. ST segment elevation in lead aVR with less ST segment elevation in lead V(1). J Am Coll Cardiol 2001;38:1348-54.

24. Yan AT, Yan RT, Kennelly BM, et al. Relationship of ST elevation in lead aVR with angiographic findings and outcome in non-ST elevation acute coronary syndromes. Am Heart J 2007;154:71-8.

25. Palazzuoli A, Deckers J, Calabrò A, et al. Brain natriuretic peptide and other risk markers for outcome assessment in patients with non-ST-elevation coronary syndromes and preserved systolic function. Am J Cardiol 2006;98:1322-8.

26. Cosin-Sales J, Kaski JC, Christiansen M, et al. Relationship among pregnancy associated plasma protein-A levels, clinical characteristics, and coronary artery disease extent in patients with chronic stable angina pectoris. Eur Heart $J$ 2005:26:2093-8

27. Kumar SP, Brewington SD, O'Brien KF, et al. Clinical correlation between increased lung to heart ratio of technetium- $99 \mathrm{~m}$ sestamibi and multivessel coronary artery disease. Int J Cardiol 2005;101:219-22.

28. Isma'eel H, Hamirani YS, Daga N, et al. Determinants of left main calcifications in a cohort of 2136 diabetes patients. Int J Cardiol 2010;142:e48-50.

29. Kunz GA, Liang G, Cuculi F, et al. Circulating endothelial progenitor cells predict coronary artery disease severity. Am Heart J 2006;152:190-5.

30. Rubinshtein R, Halon DA, Jaffe $R$, et al. Relation between obesity and severity of coronary artery disease in patients undergoing coronary angiography. Am J Cardiol 2006; 97:1277-80.

31. Uthamalingam S, Zheng $\mathrm{H}$, Leavitt $\mathrm{M}$, et al. Exercise-induced ST-segment elevation in ECG lead aVR is a useful indicator of significant left main or ostial LAD coronary artery. JACC Cardiovasc imaging 2011:4:176-86.

32. Wijns W, Kolh P, Danchin N, et al. Guidelines on myocardial revascularization. Eur Heart J 2010;31:2501-55.

33. Serruys P, Morice MC, Kappetein AP, et al; SYNTAX Investigators. Percutaneous coronary intervention versus coronary-artery bypass grafting for severe coronary artery disease. N Engl J Med 2009;360:961-72.

34. Naik H, White AJ, Chakravarty T, et al. A meta-analysis of 3,773 patients treated with percutaneous coronary intervention or surgery for unprotected left main coronary artery stenosis. JACC Cardiovasc Interv 2009;2:739-47.

35. Hueb W, Lopes NH, Gersh B, et al. A randomized controlled clinical trial of 3 therapeutic strategies for multivessel coronary artery disease. Circulation 2007;115:1082-9.

36. Giannoglou GD, Antoniadis AP, Chatzizisis YS, et al. Prevalence of Narrowing $>50 \%$ of the left main coronary artery among 17,300 patients having coronary angiography. Am J Cardiol 2006;98:1202-5.

37. Conley MJ, Ely RL, Kisslo J, et al. The prognostic Spectrum of left main stenosis. Circulation 1978;57:947-52.

38. Salem BI, Terasawa M, Mathur VS, et al. Left main coronary artery ostial stenosis: clinical markers, angiographic recognition and distinction from left main disease. Cathet Cardiovasc Diagn 1979;5:125-34.

39. Halkin A, Singh $M$, Nikolsky $E$, et al. Prediction of mortality after primary percutaneous coronary intervention. The CADILLAC Risk Score. J Am Coll Cardiol 2005; 45:1397-405. 
40. Chaitman B, Bourassa M, Davies K. Angiographic prevalence of high-risk coronary artery disease in patient subsets (CASS). Circulation 1981;64:360-7.

41. Zhong B, Liu Z, Su L, et al. Comparison of prognostic value of different risk score methods on outcome of acute coronary syndrome. Clin Cardiol 2009;32:434-8.

42. Haim M, Battler A, Behar S, et al. Acute coronary sindrome complicated by syntomatic and asyntomatic heart failure: does current treatment comply with guidelines? Am Heart J 2004;147:859-64.

43. Boden WE, O'Rourke RA, Teo KK, et al. The evolving pattern of symptomatic coronary artery disease in the United States and Canada: baseline characteristics of the clinical outcomes utilizing revascularization and aggressive DruG evaluation (COURAGE) trial. Am J Cardiol 2007;99:208-12.

44. Chaitman B, Bourassa MG, Davis K, et al. Angiographic prevalence of high risk coronary artery disease in patients subsets. Circulation 1981;64:360-7.

45. Gorgels $\mathbf{P}$, Engelen DJ, Wellens HJ. Lead aVR, a mostly ignored but very valuable lead in clinical electrocardiography, J Am Coll Cardiol 2001;38:1355-6.

46. Vorobiof G, Ellestad MH. Lead aVR: dead or simply forgotten? JACC Cardiovasc Imaging 2011:4:187-90.

47. Yamaji H, Iwasaki K, Kusachi S, et al. Prediction of acute left main coronary artery obstruction by 12-lead electrocardiography: ST segment elevation in lead aVR with less ST segment elevation in lead V1. J Am Coll Cardiol 2001;38:1348-54.

48. Taglieri N, Marzocchi A, Saia F, et al. Short- and long-term prognostic significance of ST-Segment elevation in lead aVR in patients with Non-ST-segment elevation acute coronary syndrome. Am J Cardiol 2011:108:21-8.

49. Savonitto $\mathbf{S}$, Ardissino D. Granger CB prognostic value of the admission electrocardiogram in acute coronary syndromes. JAMA 1999;281:707-13.

50. Severi S, Orsini E, Marraccini P, et al. The basal electrocardiogram and the exercise stress test in assessing prognosis in patients with unstable angina. Eur Heart $J$ 1988:9:441-6

51. Hamm CW, Bassand JP, Agewall S, et al. ESC guidelines for the management of acutecoronary syndromes in patients presenting without persistent ST-segment elevation. The task force for the management of acute coronary syndromes (ACS) in patients presenting without persistent ST-segment elevation of the European Society of Cardiology (ESC). Eur Heart J 2011;32:2999-3054.

52. Steg PG, Dabbous OH, Feldman LJ, et al. Global registry of acute coronary events investigators. Determinants and prognostic impact of heart failure complicating acute coronary syndromes: observations from the Global registry of acute coronary events (GRACE). Circulation 2004;109:494-9.

53. Mazzanti M, Germano G, Kiat $\mathrm{H}$, et al. Identification of severe and extensive coronary artery disease by automatic measurement of transient ischaemic dilation of the left ventricle in dual-isotope myocardial perfusion SPECT. JACC 1996;27:1612-20.

54. Shiba C, Chikamori T, Hida S, et al. Important parameters in the detection of left main trunk disease using stress myocardial perfusion imaging. J Cardiol 2009:53:43-52.

55. Yao SS, Shah A, Bangalore S, et al. Transient ischaemic left ventricular cavity dilation is a significant predictor of severe and extensive coronary artery disease and adverse outcome in patients undergoing stress echocardiography $\mathrm{Am} \mathrm{Soc}$ Echocardiogr 2007;20:352-8.

56. Valdiviezo C, Motivala AA, Hachamovitch $\mathrm{R}$, et al. The significance of transient ischemic dilation in the setting of otherwise normal SPECT radionuclide myocardial perfusion images. J Nucl Cardiol 2011;18:220-9.

57. D'Ascenzo F, Bollati M, Clementi F, et al. Incidence and predictors of coronary stent thrombosis: evidence from an international collaborative meta-analysis including 30 studies, 221,066 patients, and 4276 thromboses. Int J Cardiol 2012.

58. D'Ascenzo F, Biondi-Zoccai G, Reed MJ, et al. Incidence, etiology and predictors of adverse outcomes in 43,315 patients presenting to the emergency department with syncope: an international meta-analysis. Int J Cardiol 2011.

59. Ross JS, Mulvey GK, Stauffer B, et al. Statistical models and patient predictors of readmission for heart failure: a systematic review. Arch Intern Med 2008; 168:1371-86

\section{Heart impact factor}

Heart now has an impact factor of $\mathbf{4 . 7 0 6}$ which reflects the high quality of the publication in the cardiology field. If you would like to add to this quality, then submit your paper at heart.bmj.com. 


\section{Heart}

Prevalence and non-invasive predictors of left main or three-vessel coronary disease: evidence from a collaborative international meta-analysis including 22 ?740 patients

Fabrizio D'Ascenzo, Davide Giacomo Presutti, Elisa Picardi, Claudio Moretti, Pierluigi Omedè, Filippo Sciuto, Marco Novara, Andrew T Yan, Shaun Goodman, Nitin Mahajan, Masami Kosuge, Alberto Palazzuoli, Gwo-Ping Jong, Hussain Isma'eel, Matthew J Budoff, Ronen Rubinshtein, Henry Gewirtz, Matthew J Reed, Pierre Theroux, Giuseppe

Biondi-Zoccai, Maria Grazia Modena, Imad Sheiban and Fiorenzo Gaita

Heart 2012 98: 914-919

doi: 10.1136/heartjnl-2011-301596

Updated information and services can be found at:

http://heart.bmj.com/content/98/12/914

These include:

References This article cites 56 articles, 12 of which you can access for free at: http://heart.bmj.com/content/98/12/914\#BIBL

Email alerting service

Receive free email alerts when new articles cite this article. Sign up in the box at the top right corner of the online article.

Topic Articles on similar topics can be found in the following collections

Collections

Drugs: cardiovascular system (8839)

Metabolic disorders (1029)

\section{Notes}

To request permissions go to:

http://group.bmj.com/group/rights-licensing/permissions

To order reprints go to:

http://journals.bmj.com/cgi/reprintform

To subscribe to BMJ go to:

http://group.bmj.com/subscribe/ 